\title{
Pattern use of Non-steroidal Anti-inflammatory Drugs among Saudi Community: Patients' Perspective
}

\author{
Amani Abdullah Bahdailah*, Pharma- \\ ceutical Care Services, King Abdullah Bin \\ Abdulaziz University Hospital, Riyadh, \\ SAUDI ARABIA.

\section{Correspondence: \\ Dr. Amani Abdullah Bahdailah, Msc \\ Clin Pharm, Pharm D, Head of Education and Training Section, Pharmaceutical care services, King Abdullah Bin Abdulaziz University Hospital, Riyadh-13412, SAUDI ARABIA.}

Phone no: +966 505235901

E-mail: abahdealah@yahoo.com

Received: 19-10-2018;

Accepted: 26-1-2019

Copyright: ๑ the author(s),publisher and licensee Pharmacology, Toxicology and Biomedical Reports. This is an open-access article distributed under the terms of the Creative Commons Attribution NonCommercial License, which permits unrestricted non-commercial use, distribution, and reproduction in any medium, provided the original work is properly cited.

This is an open access article distributed under the terms of the Creative Commons Attribution-NonCommercial-ShareAlike 4.0 License

Access this article online

\begin{tabular}{|c|c|}
\hline & www.ptbreports.org \\
& \\
\hline
\end{tabular}

\begin{abstract}
Objectives: In this study, we aimed to explore the utilization of public use of non-steroidal anti-inflammatory drugs (NSAIDs) among the participants from the major metropolitan areas in Saudi Arabia. Methodology: This is a cross-sectional study conducted over a period of 6 months. The study questionnaire was randomly distributed via digital media using Survey Monkey system to individuals in the Kingdom of Saudi Arabia. The questionnaire comprised 24 questions related to demographic data; age; education; socioeconomic status; weight; history of chronic disease; history of pain; frequency, type and dosage of NSAIDs; and indication for the use of NSAIDs. The survey web link was distributed via social media to a convenient sample of participants. Data were tabulated and analyzed by using SPSS version 13 software. Results: The survey questionnaire was distributed to 3000 patients and a total of 500 participants responded, making the response rate as $16.6 \%$. Of them, the highest percentage of responders belonged to the age group of above 40 years $(52.63 \%, n=263)$. Majority of the responders had a university degree $(66.20 \%, n=329)$. Of all the responders, $54 \%(n=272)$ did not use painkillers daily, whereas $43.33 \%(n=216)$ took painkillers daily; $2.26 \%(n=11)$ of the responders did not remember. Around $87 \%(n=433)$ of the responders tool an average of $1-3$ NSAIDs daily, $11.44 \%(n=57)$ took 4-7 NSAIDs daily and $1.49 \%(n=7)$ responders took 8-12 NSAIDs daily without a prescription. Furthermore, $0.50 \%(n=2)$ of the responders took more than 12 NSAIDs per day. Conclusion: The NSAIDs are highly utilized in the Kingdom of Saudi Arabia. Therefore, the number of awareness programs for the public about the side effects of short- and long-term use of NSAIDs is highly recommended in Saudi Arabia.

Key words: Pattern, Use, Non-steroidal Anti-inflammatory Drugs, Patient, Saudi Arabia.
\end{abstract}

\section{INTRODUCTION}

Non-steroidal anti-inflammatory drugs (NSAIDs) are the most widely used therapeutic agents that are taken alone or in combination with other types of the drugs. They are used to relieve symptoms of many clinical indications including short- and long-term pain. The primary use of NSAIDs is in the treatment of fever and headache. ${ }^{1}$ In the elderly population, chronic pain is a significant issue. Approximately $30 \mathrm{mil}$ lion people use NSAIDs daily for the treatment of pain $;^{2}$ of them, almost $50 \%$ are above the age of 65 years. ${ }^{3,4}$ NSAIDs are used in both acute and chronic musculoskeletal pain including low back pain. ${ }^{4-6}$ They might also be used in chronic spinal pain; however, the efficacy of NSAIDs has been evaluated in clinical trials conducted only for a few days. ${ }^{7-9}$ Furthermore, NSAIDs are widely used to treat various inflammatory conditions such as rheumatoid arthritis and osteoarthritis. ${ }^{10}$ Samuelsen et al. (2015) reported the use of analgesics in the general Norwegian population, their change over time and high-risk use, which was called "The Tromso Study." Their study was aimed to estimate the prevalence of use of over the counter (OTC) medications and prescription analgesics. They discussed the change in the use of analgesics over time and the prevalence of use in the presence of potential contraindications and pharmacodynamic drug interactions. Their results also showed that there was a tendency of worsening health, more pain and less education across the analgesic user group than that of the nonuser group. ${ }^{11}$ Garofalo et al. (2015) studied the use of self-medication among parents in Italy. They performed a cross-sectional survey on the prevalence, the determinants and the reasons of oral medication use without the prescription of a physician among a random sample of 672 parents of students attending randomly in selected public schools in Italy. Their results showed that $69.2 \%$ practiced self-medication at least once. The odds of having performed self-medication were higher in females, in the younger population, in those who have had a health problem in the preceding year and were lower in respondents with a middle or lower level of school education. Among those reporting experience of self-medication, $53.4 \%$ have practiced at least once in the last year and this was more likely for those who have had a health problem. NSAIDs were more frequently used without a prescription in the previous year. Two-thirds of the participants inappropriately self-medicated during the last year at least once. Of those who did not report self-medication, $13.1 \%$ were willing to practice it. Females were more prepared and those who attended secondary school of education were less ready to practice self-medication. The frequency of oral self-medication was quite high and in most cases inappropriate with a potential impact on the health status. ${ }^{12}$ Almalak et al. (2014) studied the attitude of students in Saudi Arabia toward 
the use of OTC medicine during exams. Approximately, 1596 students participated in this survey, of whom, 829 (51.9\%) were university students and 767 (48.1\%) were high school students. Their results showed that the use of OTC as NSAIDs was higher among high school female students who were in the age group of 16-18 years. Overall, university students were found to have a better knowledge about the safety of OTC medicine. ${ }^{13}$ Therefore, in this study, we aimed to explore the utilization of public use of NSAIDs among participants from major metropolitan areas in Saudi Arabia.

\section{METHOD}

This is a cross-sectional study conducted for a period of 6 months. The study questionnaire was developed to evaluate the use of NSAIDs in several major metropolitan areas in the Kingdom of Saudi Arabia. The questionnaire was tested on 32 patients and was re-designed. Th re-designed questionnaire was randomly distributed using the Survey Monkey system to individuals via social networking means. The questionnaire comprised 24 questions. The sample size was calculated using Raosoft method assuming a population of 20,000 individuals, with a margin of error as $5 \%$, a response distribution of $50 \%$ and $95 \%$ confidence interval. ${ }^{14}$ The sample size was determined to be 377 individuals. Adult individuals in the age group of 18-65 years were included in this study. Children and geriatric patients above 65 years were excluded from participation. The survey consisted of demographic data; age; education; socioeconomic status; weight; history of chronic disease; history of pain; frequency, type and dosage of NSAIDs; and indication for the use of NSAIDs. The survey web link was distributed via social media to a convenient sample of participants from July to November 2016. Data were tabulated and analyzed by using SPSS version 13 software.

\section{RESULTS}

In this study, 3000 patients received the survey questionnaire and a total of 500 patients responded, making the response rate as $16.6 \%$. Of these, the highest percentage of responders were in the age group of above 40 years $(52.63 \% n=263)$, followed by those in the age group of $26-40$ years $(42.11 \% n=210)$. Majority of the responders had obtained a university degree $(66.20 \%, n=329)$, followed by high school diploma $(21.73 \%$, $n=108)$, intermediate degree $(1.41 \%, n=7)$ and finally those without education $(0.40 \%, n=2)$. Around $62 \%$ of the responders were employed and the rest were not. Approximately $44 \%(n=221)$ of the responders had their monthly income as above 15,000 Saudi Riyals (SRs) per month, followed by those with a monthly income ranging from 7000 to 15,000 SRs $(33.60 \%, n=165)$ and those with a salary ranging from 2000 to 7000 SRs and less than 2000 SRs (17\%, $n=85$ and 5.87\%, $(n=29$, respectively) (Table 1).

Among the responders; 63\% $(n=315)$ did not visit the emergency room (ER) because of the acute pain attack in the previous year, $31.72 \%$ $(n=158)$ visited the ER for $1-4$ times and $3.43 \%(n=17)$ did visit the ER for 5-8 times. Only $1.82 \%(n=9)$ visited ER more than 8 times in the last year. The number of responders who underwent surgical operations in the previous 5 years was $62 \%(n=312)$, whereas $36.14 \%(n=180)$ did operations from 1 to 4 times during the last 5 years. Furthermore, $0.8 \%$ $(n=4)$ of the responders underwent at least 5 and 8 operations. In the previous 5 years. Around $58 \%(n=289)$ of the responders did not suffer from chronic diseases, whereas $42.11 \%(n=211)$ were suffering from chronic diseases. Approximately 60\% $(n=296)$ of the responders suffered from headache at least 1-4 times per month, followed by no attacks (18.15\%, $n=91$ ), whereas $14.11 \%$ of the responders were suffering headaches at least 5-8 times per month. Around $8.47 \%(n=42)$ of the responders suffered from headache more than 8 times per month (Table 2).

According to our results, the daily usage of painkillers was not very com- mon among the responders. Around 54\% $(n=272)$ did not use painkillers daily, whereas $43.33 \%(n=216)$ took painkillers daily; $2.26 \%(n=11)$ did not remember. Approximately $69.2 \%$ of the responders practiced self-medication at least once. Furthermore, an average of 1-3 medications were taken daily by around $87 \%(n=433)$ of the responders, $11.44 \%$ $(n=57)$ took $4-7$ medications daily and only $1.49 \%(n=7)$ took $8-12$ medications daily without a prescription. Furthermore, $0.50 \%(n=2)$ of the responders took more than 12 medications per day. According to our results, several types of NSAIDs were used by the participants: 39.92\% ( $n=199$ ) used Panadol $^{\circ}$ and Voltaren $50 \mathrm{mg}$ and $9.55 \%(n=48)$ used Panadol, Brufen 600 and Voltaren $50 \mathrm{mg}$. Furthermore, around $10 \%(n=46)$ of the responders used Panadol, Brufen 400, and Ponstan Around $24.63 \%(n=123)$ of the responders did not use any of the aforementioned drugs (Table 3).

\section{DISCUSSION}

Several publications had been published about one type of medications and related patients knowledge or perception or practice. ${ }^{15-17}$ This research is very important to determine patient situation related to the medicines, subsequently setup pharmacy strategic plan to correct and improve the condition. ${ }^{18}$ The results of this survey showed that most of the responders had good education and adequate economic incomes. Only one-third of the responders visit the ER due to the pain. Two-third of them suffered from headache several times in a month. As a result, around half of the respondents were taking painkillers daily. This shows that there is a high usage of OTC medicines without doctor's consultation. Moreover, misuse of medications is related to the weak knowledge regarding medications of pain management. By studying the relationship between the multiple headaches suffering individuals and the types of non-NSAIDs used during the headache, it showed that the group who were not experiencing headache, they did not use any of the mentioned

\begin{tabular}{|l|c|}
\hline \multicolumn{2}{|l|}{ Table 1: Sociodemographic characteristic of the respondents. } \\
\hline Age (years) & $n(\%)$ \\
\hline $15-25$ & $27(5.26 \%)$ \\
\hline $26-40$ & $210(42.11 \%)$ \\
\hline$>40$ & $263(52.63 \%)$ \\
\hline The education level in the Participants & \\
\hline Education level & $n(\%)$ \\
\hline University & $329(66.20 \%)$ \\
\hline High school education & $108(21.73 \%)$ \\
\hline Intermediate & $7(1.41 \%)$ \\
\hline Without & $2(0.40 \%)$ \\
\hline Employment status of participants & $n(\%)$ \\
\hline Employment & $221(43.52 \%)$ \\
\hline Yes & $n(\% .87 \%)$ \\
\hline No & $61.82 \%$ \\
\hline Monthly income distribution among participants & $38.18 \%$ \\
\hline Monthly Income (SR) & \\
\hline$<2000$ & \\
\hline $2000-7000$ & \\
\hline $7000-15000$ & \\
\hline$>15000$ & \\
\hline
\end{tabular}




\begin{tabular}{|c|c|c|}
\hline $\begin{array}{l}\text { How Many Times You Visited The Emergency } \\
\text { Room For An Acute Pain in the Past year? }\end{array}$ & Frequency & Percent \\
\hline None & 316 & $63.20 \%$ \\
\hline From 1 - 4 times & 158 & $31.60 \%$ \\
\hline From $5-8$ times & 17 & $3.40 \%$ \\
\hline More than 8 times & 9 & $1.80 \%$ \\
\hline Answered questions & 500 & \\
\hline Skipped questions & 0 & \\
\hline \multicolumn{3}{|l|}{$\begin{array}{l}\text { Number of individuals suffering from chronic } \\
\text { diseases }\end{array}$} \\
\hline Yes & 289 & $57.80 \%$ \\
\hline No & 211 & $42.20 \%$ \\
\hline Answered questions & 500 & \\
\hline Skipped questions & 0 & \\
\hline \multicolumn{3}{|l|}{$\begin{array}{l}\text { How many operations done to you in the past } \\
\text { five years? }\end{array}$} \\
\hline None & 312 & $62.40 \%$ \\
\hline From $1-4$ operations & 180 & $36.00 \%$ \\
\hline From $5-8$ operations & 4 & $0.80 \%$ \\
\hline More than 8 & 4 & $0.80 \%$ \\
\hline Answered questions & 500 & \\
\hline Skipped questions & 0 & \\
\hline \multicolumn{3}{|l|}{$\begin{array}{l}\text { Number of times you got PAIN/Headache per } \\
\text { month }\end{array}$} \\
\hline None & 90 & $18.00 \%$ \\
\hline From 1 - 4 times per month & 296 & $59.20 \%$ \\
\hline From 5 - 8 times per month & 72 & $14.40 \%$ \\
\hline More than 8 times per month & 42 & $8.40 \%$ \\
\hline Answered questions & 500 & \\
\hline Skipped questions & 0 & \\
\hline
\end{tabular}

medication. Responders who suffered headache at least 1-4 times per month were more likely to use Panadol' only during headache. This result is contradictory to those published by Stosic et al. (2011); they showed that there was a frequent use of analgesics, such as Voltaren and or Brufen. ${ }^{19}$ Respondents who experienced headache at least 5-8 times per month were more likely to use Panadol than that of other NSAIDs. However, respondents who experienced headache more than 8 times per month were more likely to use NSAIDs without prescriptions. Statistical analysis revealed a strong association between the number of headaches per month and the use of nonprescribed NSAIDs ( $P$-value<0.000). This explains the use of NSAIDs without a prescription. Besides, we compared this study with the study of Garafelo et al. (2015), our results declared a significant finding about the relation between education and the abuse of NSAIDs used. However, the higher education respondents, the lower use of NSAIDs and pain killers without consultation.

According to the age group, respondents of age group between 15-25 years, were more likely afford pain without taking any treatment. The age group between 26-40 years, were able to tolerate pain without the use of any treatment and less likely to use a pervious prescribed medicine for the same pain symptoms. Respondents in the age group over 40 years
Table 3: Pattern use of non-steroidal anti-inflammatory drugs.

\begin{tabular}{|c|c|c|}
\hline Items & Number & Percentages \\
\hline \multicolumn{3}{|l|}{ Are you suing pain killer daily } \\
\hline No & 272 & $54.51 \%$ \\
\hline Yes & 216 & $43.29 \%$ \\
\hline I do not remember & 11 & $2.20 \%$ \\
\hline Answered questions & 499 & \\
\hline Skipped questions & 1 & \\
\hline \multicolumn{3}{|l|}{$\begin{array}{l}\text { Average number of medications taken by } \\
\text { individuals daily }\end{array}$} \\
\hline From 1 - 3 medications daily & 433 & $86.77 \%$ \\
\hline From 4 - 7 medications daily & 57 & $11.42 \%$ \\
\hline From 8 - 12 medications daily & 7 & $1.40 \%$ \\
\hline More than 12 & 2 & $0.40 \%$ \\
\hline Answered questions & 499 & \\
\hline Skipped questions & 1 & \\
\hline \multicolumn{3}{|l|}{ Types of NSAIDS used by each individual } \\
\hline Panadol $^{\oplus}$ and voltaren ${ }^{\star} 50 \mathrm{mg}$ & 199 & $39.80 \%$ \\
\hline Panado $l^{\circ}$ and brufen ${ }^{\circ} 400$ and ponstan ${ }^{\circ}$ & 46 & $11.00 \%$ \\
\hline Panadol $^{\circ}$ and brufen ${ }^{\circ} 600$ and voltaren ${ }^{\circ} 50 \mathrm{mg}$ & 48 & $12.00 \%$ \\
\hline Panadol $^{\circ}$ and olfen ${ }^{\circ} 100$ and celebrix ${ }^{\circ} 100 \mathrm{mg}$ & 10 & $2.00 \%$ \\
\hline Panadol $^{\star}$ and brufen 600 and celebrix ${ }^{\circ} 100 \mathrm{mg}$ & 15 & $3.00 \%$ \\
\hline $\begin{array}{l}\text { Tylenol } 3 \text { and tramadol }{ }^{\oplus} 50 \mathrm{mg} \text { and celbrex } \\
100 \mathrm{mg}\end{array}$ & 22 & $4.40 \%$ \\
\hline I use all those mentioned medications freely & 13 & $3.20 \%$ \\
\hline $\begin{array}{l}\text { I am NOT using any of those mentioned } \\
\text { medications }\end{array}$ & 123 & $24.60 \%$ \\
\hline $\begin{array}{l}\text { I use Other brands from foreign countries gives } \\
\text { the same effect. }\end{array}$ & 0 & $0.00 \%$ \\
\hline Answered questions & 500 & \\
\hline Skipped questions & 0 & \\
\hline
\end{tabular}

were more likely to visit the physician in case of pain and less likely to take medicine from a trusted pharmacist. After testing correlation, it was found to be significant $(P$-value $<0.009)$. In the case of education level and action taken when feeling sick, we found no statistical difference between the two. The correlation between education level of the respondents and their use a particular type of medication, showed that intermediate and high level education respondents, were stopping their medication without consultation and low number of respondents consult a pharmacist before stopping their medication. The respondents with a university level of education were more likely to consult physicians and less likely to ask a pharmacist or stop the medication without consultation. The respondents with a postgraduate level of education, were more likely to read the leaflet for the possibility of having side effects from the medicine itself, which was found to be significantly correlated $(P$-value $<0.024)$.

\section{CONCLUSION}

There was a high utilization of Non-Steroidal Anti-inflammatory with Saudi population. Targeting of public awareness campaigns about the appropriate usage the medications. Future studies may be conducted to 
measure the impact of education program for the usage of Non-Steroidal Anti-inflammatory in the Kingdom of Saudi Arabia.

\section{ACKNOWLEDGEMENT}

None.

\section{CONFLICT OF INTEREST}

The authors declare no conflicts of interest.

\section{ABBREVIATIONS}

SPSS: Statistical Packages for Social Sciences; WHO: World health Organization.

\section{REFERENCES}

1. McGettigan P, Henry D. Use of Non-Steroidal Anti-Inflammatory Drugs That Elevate Cardiovascular Risk: An Examination of Sales and Essential Medicines Lists in Low-, Middle and High-Income Countries. PLoS Med. 2013;10(2):e1001388.

2. Park KE, Qin Y, Bavry AA. Nonsteroidal anti-inflammatory drugs and their effects in the elderly. Aging Health. 2012;8(2):167-77.

3. Thomas E, Peat G, Harris L, Wilkie R, Croft PR. The prevalence of pain and pain interference in a general population of older adults: Cross-sectional findings from the North Staffordshire Osteoarthritis Project (NorStOP). Pain. 2004;110(1):361-8

4. Visser LE, Graatsma HH, Stricker BHC. Contraindicated NSAIDs are frequently prescribed to elderly patients with peptic ulcer disease. Br J Clin Pharmacol. 2002;53(2):183-8.

5. Ekman EF, Koman LA. Acute pain following musculoskeletal injuries and orthopaedic surgery: Mechanisms and management. Instr Course Lect. 2005;54:2133.

6. Teslim OA. Side Effects of Non-Steroidal Anti-Inflammatory Drugs: The Experience of Patients with Musculoskeletal Disorders. Am J Heal Res.
2014;2(4):106-12. Hickey RF. Chronic low back pain: A comparison of diflunisa with paracetamol. N Z Med J. 1982;95(707):312-4

7. Videman T, Osterman K. Double-blind parallel study of piroxicam versus indomethacin in the treatment of low back pain. Ann Clin Res. 1984;16(3):156-60

8. Berry H, Bloom B, Hamilton EB, Swinson DR. Naproxen sodium, diflunisal and placebo in the treatment of chronic back pain. Ann Rheum Dis. 1982;41(2):12932.

9. Rao P, Knaus EE. Evolution of Nonsteroidal Anti-inflammatory Drugs (NSAIDs): Cyclooxygenase (COX) inhibition and beyond. J Pharm Pharm Sci 2008;11(2):81s-110s.

10. Samuelsen PJ, Slørdal L, Mathisen UD, Eggen AE. Analgesic use in a Norwegian general population: change over time and high-risk use-The Tromsø Study. BMC Pharmacol Toxicol. 2015;16(1):16.

11. Garofalo L, DiGiuseppe G, Angelillo IF. Self-Medication Practices among Parents in Italy. Biomed Res Int. 2015;2015:1-8.

12. Almalak H, Albluwi Al, Alkhelb DA, Alsaleh HM, Khan TM, Hassali MAA, et al. Students' attitude toward use of over the counter medicines during exams in Saudi Arabia. Saudi Pharm J. 2014;22(2):107-12.

13. Creative Research Systems. Sample Size Calculator. 2012. [cited 2019 May 7] Available from: http://www.raosoft.com/samplesize.html

14. Fouad F, Doughan A, Alomi YA, Iflaifel MH. Pharmacist's Awareness and Knowledge of Reporting Adverse Drug Reactions in Saudi Arabia. Int J Pharm Heal Sci. 2019;2(1):60-5.

15. Alenazi AB, Alsharidah MS, AINajiar AH, Alghazy SA, Alqadi AAA, Marzouk A. Perceptions and Knowledge of Storing Medications at Home in Al-Qassim Region, Saudi Arabia Afaf. Int J Pharm Heal Sci. 2019;2(1):79-85.

16. Alomi YA, Alhathlool SA, Almulhim MI, Ali A, Aboshalaf Y, Alethan M. Patient's Perception and Attitude of Pharmacist during Pharmacy Visits in Saudi Arabia Int J Pharm Heal Sci. 2018;1(1):38-43.

17. Alomi YA, Alghamdi SJ, Alattyh RA, Elshenawy RA. The Evaluation of Pharmacy Strategic Plan in Past 2013-2016 and Forecasting of New Vision 2030 at Ministry of Health in Saudi Arabia. J Pharm Pract Community Med. 2018;4(2):93-101.

18. Stosic R, Dunagan F, Palmer H, Fowler T, Adams I. Responsible self-medication: perceived risks and benefits of over-the-counter analgesic use. Int J Pharm Pract. $2011 ; 19(4): 236-45$. 